\title{
ETHICAL CHALLENGES IN NANOMETROLOGY
}

Nanometrology is an intrinsic and fast developing part of nanoscience. Given the huge diversity of nanostructures ranging from large molecules from about 10 atoms to structures from $10^{5}$ atoms (particles of the size $\leq 100 \mathrm{~nm}$ ), broader investigations in this area cannot be exactly scrutinized nor repeated by the existing capacities. This gave rise to the initiative for reproducibility that aims to avoid simplified approaches, plagiarism and other phenomena that are often triggered by the "publish or perish" philosophy, as well as business practices of predatory journals. In this paper, we discuss two case studies illustrating how to solve these problems: a study of the structural stability of nanoparticles by three complementary methods, and a design of reliable nanoparticle gas sensors used in environment or medicine.

Keywords: nanometrology, nanoparticles, reproducibility of measurements, structural stability, gas sensors

\section{Introduction to nanometrology}

Nanoscience and nanotechnology $(\mathrm{N} \& \mathrm{~N})$ introduced a way of building molecular structures by the bottom-up approach. It provides opportunities in the fields of information technology, medicine, and new materials. The main aims of this branch are design, preparation, manipulation, and application of materials and structures having at least one dimension within the interval from 1 to $100 \mathrm{~nm}$ [1], [2]. (For comparison the size of Si atom is $0.22 \mathrm{~nm}$ ). The mentioned interval - originally determined by a simple convention - is now widened at its lower boundary due to the appearance of graphene monolayer with the thickness of 0.34 $\mathrm{nm}$, being the most progressive structure of the present material research. Basic nano-objects are molecules, atomic clusters, nanoparticles (NPs), nanowires, nanolayers, etc., which represent the building blocks of devices and structures. Characterized by a well-known statement by R. Smalley (2000) - nanotechnology is the art of building devices at the ultimate level of finesse.

The high scientific relevance of N\&N may be documented by the fact that its discoveries and inventions were awarded by three Nobel prizes in physics (E. Ruska, G. Binning and H. Rohrer; A. Fert and P. Grünberg; A. Geim and K. Novoselov) and four Nobel prizes in chemistry (R. F. Curl, H. Kroto and R. E. Smalley; W. Kohn; E. Betzig, S. W. Hell and W. E. Moerner; J. - P. Sauvage, J. F. Stoddart and B. L. Feringa) [2].

In the field of nanometrology, attention is paid to all seven basic physical quantities - time, length, mass, electrical current, temperature, light intensity, amount of substance. Most important are, however, structure, morphology, composition, surface area, etc., of nanostructures. They are studied by almost 30 methods, divided into two basic groups [3], [4]:

a) ensemble-averaging approach (EAA) where the techniques analyse larger samples providing statistically averaged output. Examples are spectroscopies, X-ray diffraction, calorimetric methods, light scattering, etc., and

b) individual particle approach (IPA), that gives information about small samples and even individual atoms and molecules. Examples are electron and probe microscopies.

The operational space of $\mathrm{N} \& \mathrm{~N}$ is largely interdisciplinary, as it lies in the overlapping area of:

- two-dimensional, one-dimensional and zero-dimensional (2D, 1D, 0D) nanostructures with a large surface area and excellent catalytic properties, biocompatibility and low size dispersion;

- multipurpose materials with high thermal stability and controlled electrical and magnetic properties;

- complex characterization and movement for high reproducibility.

Our research is focused on spherical magnetic and biocompatible NPs belonging to iron oxide family with the good ability of self-assembly.

\footnotetext{
* ${ }^{1}$ Stefan Luby, ${ }^{2}$ Martina Lubyova, ${ }^{3}$ Ivan Kostic, ${ }^{3}$ Pavol Hrkut

${ }^{1}$ Institute of Physics SAS, Bratislava, Slovakia

${ }^{2}$ Centre of Social and Psychological Sciences SAS, Bratislava, Slovakia

${ }^{3}$ Institute of Informatics SAS, Bratislava, Slovakia

E-mail: stefan.luby@savba.sk
} 


\section{Initiative for reproducibility in nanotechnology}

The initiative aimed at reproducibility is motivated by the fact that due to the huge diversity of nanostructures that fill the space between big molecules composed from about 10 atoms to structures of $10^{5}$ atoms (size about $100 \mathrm{~nm}$ ), the interval of nanoentities cannot be either scrutinized or repeatedly investigated by existing research capacities [5], [6]. A similar situation can also be found in the field of experimental devices. We estimated that taking into consideration all sensing materials for NP gas sensors, preparation methods of nanoparticles, device and electrode configurations, it is possible to create up to 45 million types of sensors.

The initiative for reproducibility aims to avoid simplified approaches, pathological practices or plagiarism in research. "Polishing" of papers and the publication of selected positive results, the so-called "cherry picking," is also not acceptable. It can give rise to the multiplication effect when the followers extend their research starting from a good chance of their predecessors. Mueck [7] reported a clear correlation between the level of competition and tendency to select positive results in certain regions of USA. Such phenomena are fuelled by the fact that academic journals and grant agencies value more "novelty" than replication studies. Activities of predatory journals also contribute to these problems that altogether represent a large challenge for the research integrity and ethics in science and technology. In this connection, we may refer to the report [8] where among other conclusions (related to biomedicine) we find the following one: "Robust science and the validity of research findings must be the primary objective of the incentive structure. These should be valued above novel findings and publications in high-impact journals".

The reproducibility and reliability in nanotechnology depends also on the accessibility of quality control measures and various standards of measurements, procedures, reference and calibration materials, even language and terminology standards. The International Standardization Organization (ISO), Technical Committee 229 on nanotechnologies that issued almost 50 different standards plays the most important role in this area [2].

At the same time, there has been a sizeable investment in nanotechnology over the past few decades [9]. Hundreds of thousands of nanotech-startups have been created worldwide. Nanotechnology became a magical word. It is not surprising that the "gold rush" psychology prevailed and accelerated the chase for new papers and patents. Nowadays this wave is partly over, and venture capitalists understand that although nanotechnology represents a certain type of technology, the genuine nanotechnology industry does not exist. Many companies with the word "nano" in their names describe themselves now as material or semiconductor companies.

Reproducibility crisis extends to broader areas than N\&N or biomedicine [10]. Reproducible initiatives are also emerging in psychology and other branches. It is well-known that the number of retractions by scientific journals and failures to replicate high profile studies are increasing. Although the outright fraud in publications is usually low, the "softer fraud" and undisclosed flexibility in data collections is widespread. One may speculate about the introduction of the "reproducibility index" of journals, similar to the impact factor. Another initiative published recently [11] bets on interdisciplinary approaches by calling for papers combining theory, computation-simulation, and experiment in an integrated way. A decade ago such papers were less common; nowadays they become to appear. Such combination enables new discoveries, a better understanding of phenomena and, moreover, it helps to eliminate fraudulent research. Complex papers are ground-breaking, and they generate interest from experimentalists and theorists alike. However, such complex approach needs different education of new scientists. Needless to say, such approach will earlier or later become a challenge also in social sciences and humanities.

\section{How to make research reproducible}

The program R-Reproducibility could be extended to 3R-Responsibility, Reproducibility, Reliability. Responsibility in the preparation of experiments means that adequately pure materials and chemicals with the required crystalline structure are purchased or prepared. In chemical reactions fresh solutions should be used, all precursors must be stored at suitable conditions, like in vacuum or in clean boxes at certain temperatures to avoid contamination, internal diffusion, oxidation, aging, etc.

A reproducible experiment should be performed in the clean rooms of the recommended class, avoiding mixing of various material in the same reactor or deposition chamber. Stability of heat treatment or annealing must be guaranteed. Reference samples should be secured in the measurements, and even a small contribution of the substrate to the measured property of sample must be subtracted. Broad employment of the statistics of measurements is one of the principles of openness and transparency. Laboratory notebooks should be used as a matter of course.

The above mentioned and other procedures which could not be discussed in detail here may guarantee reliable and stable structure and properties of layers and multilayers, functionalized particles, devices, and sensors. It is recommended to provide experimental samples to other groups or laboratories for comparative measurements. Obviously, every such help or source of information should be adequately acknowledged. Unfortunately, these recommendations are often ignored because of commercial interests. But at least in the basic research, they would help to shorten the way towards the new results, inventions, and discoveries. 
Table 1 Basic properties of main iron oxide family members [12]

\begin{tabular}{cccc}
\hline Property & Magnetite & Maghemite & Hematite \\
\hline Formula & $\mathrm{Fe}_{3} \mathrm{O}_{4}$ & $\gamma-\mathrm{Fe}_{2} \mathrm{O}_{3}$ & $\alpha-\mathrm{Fe}_{2} \mathrm{O}_{3}$ \\
Melting point $\left[{ }^{\circ} \mathrm{C}\right]$ & $1583-1597$ & 1566 & 1350 \\
Crystalline system & cubic & cubic/tetrahed. & rhombohed./hexag. \\
Magnetism & ferro & ferri & 920 \\
Curie temp. $[\mathrm{K}]$ & 850 & $60-80$ & 956 \\
Saturation magnezation $[\mathrm{emu} / \mathrm{g}]$ & $92-100$ & & 0.3 \\
\hline
\end{tabular}

*antiferromagnetic under $260 \mathrm{~K}$ - Morin temperature



Figure $1 \mathrm{XRD}$ pattern of $\mathrm{Fe}_{2} \mathrm{O}_{3}$ sample annealed at $550^{\circ} \mathrm{C} / 1 \mathrm{~h}$ (m-maghemite, s-substrate)

In the next sections, we will describe two examples how to respond to these problems.

\section{Example 1: Structural stability of $\mathrm{Fe}_{2} \mathrm{O}_{3}$ nanoparticles studied by three complementary methods}

Iron oxide NPs are in the focus of magnetic NP research [12]. Due to biocompatibility and good magnetic properties they are used in recording and data storage, in cancer therapy and diagnostics, magnetic resonance imaging, as sensing medium in gas sensors, etc. Eight iron oxide phases have been recognized. Among them, hematite, maghemite, and magnetite are frequently used (Table 1).

Among iron oxides, $\gamma-\mathrm{Fe}_{2} \mathrm{O}_{3} \mathrm{NPs}$ with applications in material research and medicine are of pivotal importance. Therefore their thermal stability is crucial. However, it is known that they transform to $\alpha$ phase at higher temperatures $\left(\mathrm{T}_{\mathrm{T}}\right)$. The values between 200 and $500{ }^{\circ} \mathrm{C}$ are reported in the literature. (In bulk samples $\mathrm{T}_{\mathrm{T}}=500-600^{\circ} \mathrm{C}$ ) [13]. As an example, we point to the fact that temperature $\mathrm{T}_{\mathrm{T}}$ is a limiting factor of NP gas sensors of hot exhaust gases, of fire detectors, etc. Therefore we have paid to the investigation of $\mathrm{T}_{\mathrm{T}}$ of our NPs serious attention.

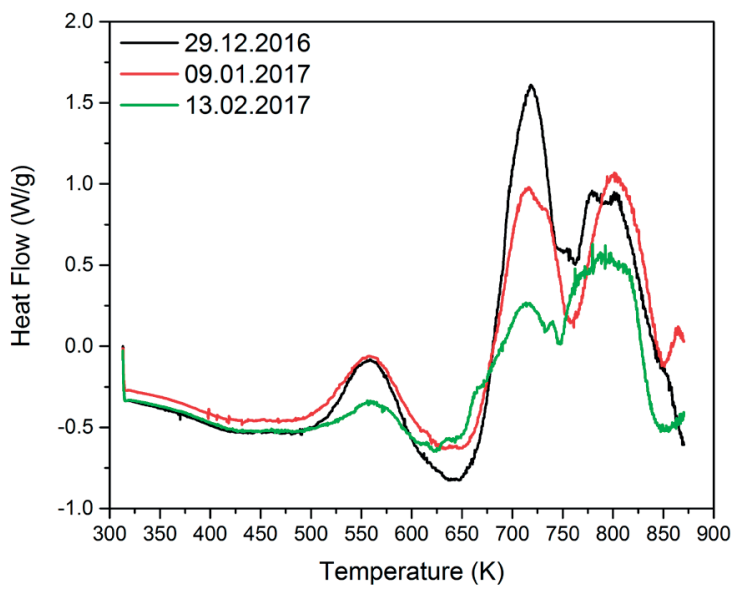

Figure 2 Repeated measurements of DSC curves of $\gamma-\mathrm{Fe}_{2} \mathrm{O}_{3} \mathrm{NPS}$

Preparation of particles by high-temperature solution phase reaction is described elsewhere [2]. The diameter of NPs is 6.4 $\mathrm{nm}$, surface protective coverage from oleic acid and oleylamine, the so-called surfactant, is $1 \mathrm{~nm}$ thick.

$\gamma \rightarrow \alpha$ transformation of NPs was studied by X-ray diffraction in the Department of multilayers and nanostructures of the Institute of Physics SAS, by differential scanning calorimetry in the Department of physics of metals of the same institute and by magnetic measurements in the Institute of Experimental Physics SAS in Kosice. Due to sharing of samples, we obtained statistically reliable data. Obviously, they are related to the particular preparation method, surfactant coverage, and diameter of particles. Details are in [14].

1. X-ray diffraction (XRD): samples were heated $1 \mathrm{~h}$ in the air between 500 and $770{ }^{\circ} \mathrm{C}$. In pure $\mathrm{Fe}_{2} \mathrm{O}_{3}$ samples maghemite (m) phase persisted up to $550{ }^{\circ} \mathrm{C}$ (Figure 1) and mixture $\mathrm{m}$ $+\mathrm{h}$ (h-hematite) was recorded only at $600{ }^{\circ} \mathrm{C}$. We assume that $\gamma$ phase is stabilized by the surface free energy [15]. For comparison in [16] $\gamma-\mathrm{Fe}_{2} \mathrm{O}_{3}$ nanoparticles showed the transition to $\alpha$ phase already at $481^{\circ} \mathrm{C}$.

2. Differential scanning calorimetry (DSC) measurements of $\mathrm{Fe}_{2} \mathrm{O}_{3}$ NP were done three times during 6 weeks. In the DSC curve (Figure 2) three groups of peaks are visible. They correspond to surfactant removal (at $560 \mathrm{~K}$ ), crystallization of 
Table 2 Saturation magnetization $\mathrm{M}_{\mathrm{s}}$ data of $\mathrm{Fe}_{2} \mathrm{O}_{3} \mathrm{NPs}$ at $50 \mathrm{kOe}$

\begin{tabular}{cc}
\hline Heating $\left[{ }^{\circ} \mathrm{C}\right]$ & $\mathrm{M}_{\mathrm{s}}[\mathrm{emu} / \mathrm{g}]$ at $300 \mathrm{~K}$ \\
\hline no & 62.5 \\
550 & 61.9 \\
600 & 21.6 \\
700 & 6.0 \\
770 & 1.6 \\
\hline
\end{tabular}
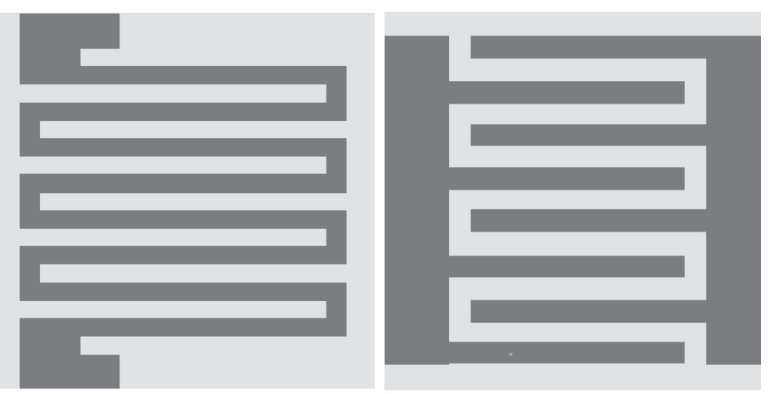

Figure 3 Design of $\mathrm{Al}_{2} \mathrm{O}_{3}$ substrate of the sensor with dimensions $2 x$ $2 \mathrm{~mm}^{2}$ equipped with comb electrodes (dark areas, right). Electrodes are composed of $20 \mathrm{~nm}$ of Ti (adhesive layer) and $200 \mathrm{~nm}$ conducting

Pt upper layer. The width of stripes is $50 \mu \mathrm{m}$. At the left side, there is a meander for in-situ heating of the sensor. It is patterned on the rear side of the substrate

NPs (at $730 \mathrm{~K}$ ), while maxima around $800 \mathrm{~K}$ correspond to $\gamma \rightarrow \alpha$ transformation finished at $870 \mathrm{~K}$, i.e. $600{ }^{\circ} \mathrm{C}$, complying to similar XRD results (Figure 1).

3. Superconducting magnetometer measured magnetic properties of NPs. The small diamagnetic contribution of $\mathrm{Si}$ substrate was subtracted from the data. Here we show the development of $\mathrm{Fe}_{2} \mathrm{O}_{3} \gamma \rightarrow \alpha$ transformation (Table 2), where the saturation magnetization $\left(\mathrm{M}_{\mathrm{s}}\right)$ of samples calibrated per mass of the measured material is given. From the sharp decrease of magnetization between 550 and $600{ }^{\circ} \mathrm{C}$ (compare the last row of Table 1) it can be concluded that there $\gamma$ phase transforms to $\alpha$. From [17] it follows that $\mathrm{M}_{\mathrm{s}}(62.5 \mathrm{emu} / \mathrm{g})$ of our small samples is surprisingly high, even higher than in larger NPs.

We may conclude that relatively high transformation temperature of our $\gamma-\mathrm{Fe}_{2} \mathrm{O}_{3}$ NPs between 550 and $600{ }^{\circ} \mathrm{C}$ is not a fluctuation. It has been proven by three independent methods, every one of them belonging to the different type of analyses. Moreover, NPs have satisfactory high magnetization which gives the evidence that preparation methods were managed at a high level.

\section{Example 2: Design of reliable nanoparticle gas sensors}

Basic semiconducting metal oxides used in gas sensors are $\mathrm{SnO}_{2}, \mathrm{TiO}_{2}, \mathrm{WO}_{3}, \mathrm{ZnO}$, and $\mathrm{Fe}_{2} \mathrm{O}_{3}$. All of them provide sufficient sensitivity of devices toward both oxidizing and reducing gases.

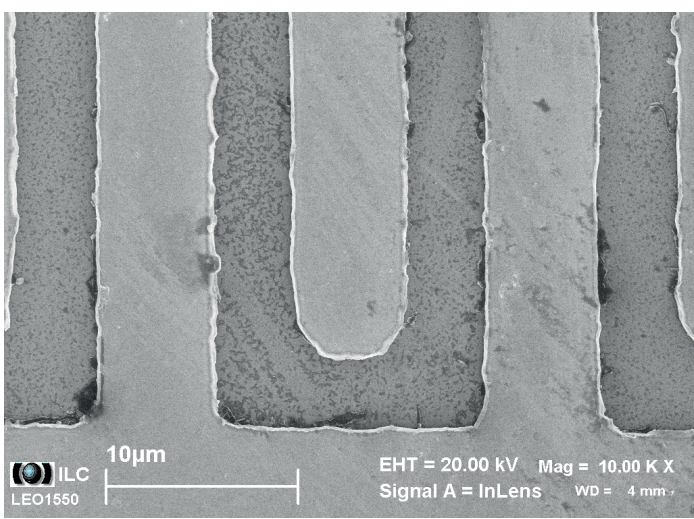

Figure $4 \mathrm{Al}_{2} \mathrm{O}_{3}$ substrate with comb electrodes about $5 \mu \mathrm{m}$ wide covered by $\mathrm{Fe}_{2} \mathrm{O}_{3}$ nanoparticles. Along the edges interruptions and voids (black spots) could be found

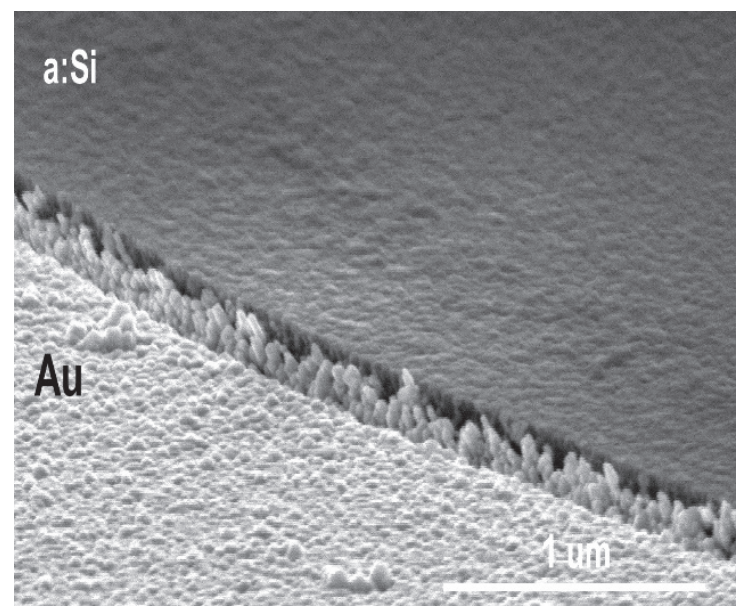

Figure 5 Au granular film. At the interface with a:Si there is ridge filled by Au pyramids

Small sensors of this type with low energy consumption are broadly used nowadays. In our laboratory, we are studying $\mathrm{Fe}_{2} \mathrm{O}_{3}$ nanoparticle sensors detecting small concentrations (1-100 ppm) of gases or vapors like $\mathrm{NO}_{2}, \mathrm{CO}$ or acetone in air. NP sensors offer high sensitivity because they have large reaction specific surface. E.g., the surface of our nanoparticles with the diameter of 6.4 $\mathrm{nm}$ is $180 \mathrm{~m}^{2} / \mathrm{g}$, being 4 times larger than that of the equivalent continuous layer.

In sensors, the substrate chips from thermally and mechanically stable $\mathrm{Al}_{2} \mathrm{O}_{3}$ ceramics are often used [18]. Silicon offers better prospects because sensors on the Si substrate could be integrated into silicon electronic circuits. The substrates are equipped with comb electrodes prepared by lithography and etching (Figure 3 ). The steps at the electrode edges, in our case $220 \mathrm{~nm}$ high, are not an acute problem if the sensing medium is prepared by deposition of layers, especially by sputtering, by spreading of the paste or by spinning the solution of the sensing material onto the substrate. These techniques guarantee reasonable „carpeting“ effect at the edges. However, with nanoparticles about 30 times smaller than the height of the step, due to the weak van der Waals forces 


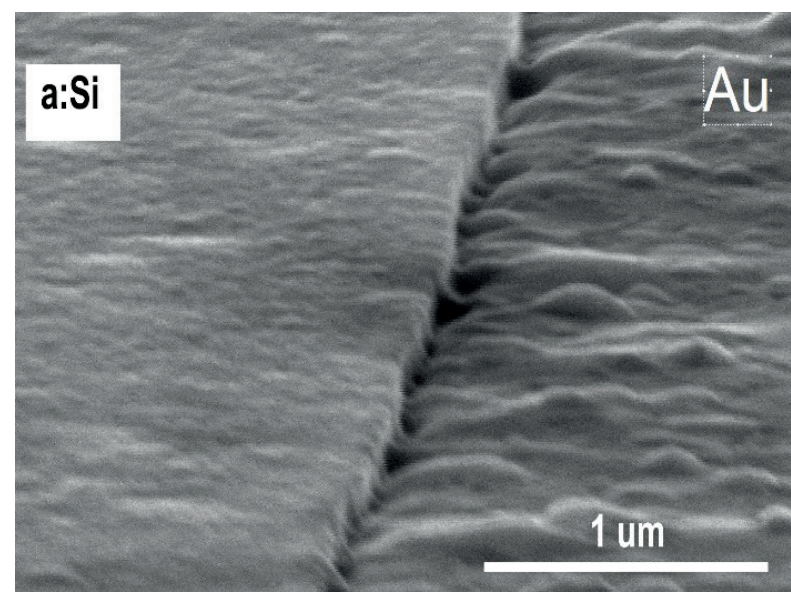

Figure 6 The sample from Figure 5 after annealing. The $100 \mathrm{~nm}$ deep ridge persists

between them $(2-4 \mathrm{~kJ} / \mathrm{mol})$, the continuous coverage of the step cannot be guaranteed. Although we have developed technique [19] using nanoparticle films formed on the water surface that is slowly sinking toward the substrate submerged in the water which is slowly pumped away, the process is not enough reliable (Figure 4). The problem may be circumvented by bevelling of the electrode steps [20]. However, then the width of electrodes is increased, and the level of miniaturization of devices is not satisfactory.

Therefore we decided to develop a technology with electrodes embedded in the substrate. First Si substrate was covered by the continuous layer of amorphous $\mathrm{Si}(\mathrm{a}: \mathrm{Si}) 0.5 \mu \mathrm{m}$ thick, which is an insulating bed of electrodes. The electrode pattern was etched into a:Si up to the depth of $380 \mathrm{~nm}$ using photolithography with a negative resist and plasma etching. The width of electrode stripes was $50,20,10,5$ or $2 \mu \mathrm{m}$. Then Au layer $350 \mathrm{~nm}$ thick was evaporated onto the surface and the excessive resist with Au layer was removed (lift-off process). Remaining Au layer was composed from 40-70 $\mathrm{nm}$ granules (Figure 5). Afterward, the samples were heated to $1100{ }^{\circ} \mathrm{C}$, i.e. above the Au melting point $\left(1064{ }^{\circ} \mathrm{C}\right)$ and Au film became smooth (Figure 6).

Although at the interface the triangle ridge about 100-120 $\mathrm{nm}$ persists, this obstacle is less detrimental for continuous NPs deposit than the high edges in previous systems. The ridge will be reduced via the mutual adjusting of the depth of etching into a:Si and the thickness of Au film. We must also elucidate how the ridge is influenced by the wetting of a:Si vertical wall by melted $\mathrm{Au}$ and how the wall shields the condensation of Au vapors.

\section{Closing remarks}

The aim of the present paper was to discuss the reasons of irreproducibility of experimental results in science in general and in nanotechnology in particular. Common principles which help to overcome these problems were introduced. Subsequently, we have provided an example how to increase the reliability of measuring the properties of nanoparticles using three different methods in three laboratories employing the sample sharing principle. The second example shows that working with very small nanoparticles in nanotechnology, we must pay attention to their interfaces with the macroscopic world and design them in an appropriate way.

\section{Acknowledgements}

Our research was supported by grants of Slovak Research and Development Agency No. APVV-14-0891, Scientific Grant Agency VEGA No. 2/0010/2015 and by CNR - SAS 2016 - 2018 common programme.

\section{References}

[1] LUbY, S., JERGEL, M., SVEC JR., P., KOSTIUK, D., IVANCO, J., MAJKOVA, E., TIMKO, M., MICUSIK, M.: Iron Oxide Nanoparticles, Preparation, Characterization, Applications. Proceedings from 19. School of Vacuum Technology, Slovak Republik, $15-25,2016$.

[2] LUBY, S.: Insight into the Nanoworld/Pohl'ady do nanosveta (in Slovak). Slovak Centre of Scientific and Technical Information, Bratislava, p. 118, 2015.

[3] MALSCH, I., EDMOND, C. (Eds.): Nanotechnology and Human Health, CRC Press, Boca Raton, 2014.

[4] MANSFIELD, E., et al. (Eds.): Metrology and Standardization for Nanotechnology. Wiley - VCH, Weinheim, 2017.

[5] Joining the reproducibility initiative, editorial. Nature Nanotech, 9(12), p. 949, 2014.

[6] LOWE, D.: Reproducibility: Crisis or Not? [online]. Available: http://blogs.sciencemag.org/pipeline/archives/2016/05/26/ [accessed 2016-10-15].

[7] MUECK, L.: Report the Awful Truth. Nature Nanotech. 8(4.10.), 693-695, 2013.

[8] Reproducibility and Reliability of Biomedical Research: Improving Research Practice. The Academy of Medical Sciences, BBSRC, MRC\&Wellcome Trust, Symposium Report, October 2015 [online]. Available: https://acmedsci.ac.uk/viewFILE/56314e40aac61. pdf [accessed 2017-08-10]. 


\section{kOMNIIKCCle}

[9] KELLEHER, K.: Here's Why Nobody's Talking about Nanotech Anymore [online]. Available: http://time.com/4068125/ nanotech-sector/.

[10] FIDLER, F., GORDON, A.: Science is in a Reproducibility Crises: How do we Resolve it? [online]. Available: https://phzs.org/ news/2013-09-science-crisis.html [accessed 2017-07-13].

[11] GLOTZER, S. C., NORDLANDER, P., FERNANDEZ, L. E.: Theory, Simulation and Computation in Nanoscience and Nanotechnology. ACS Nano, 11, 6505-6506, 2017.

[12] WU, W., WU, Z., YU, K., JIANG, C., KIM, W. - S.: Recent Progress on Magnetic Iron Oxide Nanoparticles: Synthesis, Surface Functional Strategies and Biomedical Applications. Science and Technology of Advanced Materials, 16, 023501, 2015.

[13] IVANCO, J., LUBY, S., JERGEL, M., SIFFALOVIC, P., BENKOVICOVA, M., HALAHOVETS, J., MAJKOVA, E., RELLA, R., MANERA, M. G.: Nitric Dioxide and Acetone Sensors Based on Iron Oxide Nanoparticles. Sensor Letters, 11(12), 2322-2326, 2013.

[14] LUBY, S., SVEC JR., P., BENKOVICOVA, M., JERGEL, M., TIMKO, M.: Challenges of Nanomeasurements and Complex Characterization of Iron Oxide Nanoparticles. Proceedings of APCOM, Slovak Republic, 2017, 11-16.

[15] RANDRIANANTOANDRO, N., MERCIER, A. M., HERVIEU, M., GRENECHE, J. M.: Direct Phase Transformation from Hematite to Maghemite during High Energy Ball Milling. Materials Letters, 47, 150-158, 2001.

[16] BISWAL, R. CH.: Pure and Pt-Loaded Gamma Iron Oxide as Sensor for Detection of Sub ppm Level of Acetone. Sensors and Actuators B, 157, 183-187, 2011.

[17] CAO, D., LI, H., PAN, L., LI, J., WANG, X., JING, P., CHENG, X., WANG, W., WANG, J., LIU, X. : High Saturation Magnetization of $\gamma$ - $\mathrm{Fe}_{2} \mathrm{O}_{3}$ Nano-Particles by a Facile One-Step Synthesis Approach. Scientific Reports, 6, 32360, 2016.

[18] CAPONE, S., MANERA, M. G., TAURINO, A., SICILIANO, P. A., RELLA, R., LUBY, S., BENKOVICOVA, M., SIFFALOVIC, P., MAJKOVA, E.: $\mathrm{Fe}_{3} \mathrm{O}_{4} / \gamma-\mathrm{Fe}_{2} \mathrm{O}_{3}$ Nanoparticles Multilayers Deposited by Langmuir Blodgett Technique for Gas Sensing. Langmuir, 30, 1190-1197, 2014.

[19] CHITU, L., SIFFALOVIC, P., MAJKOVA, E., JERGEL, M., LUBY, S.: Method of Fabrication of Nanoparticle Monolayers and Multilayers. Patent No. 288234, Office of Industrial Property of SR, 2014-10-08.

[20] ROTSCHILD, A., EDELMAN, F., KOMEM, Y., COSANDEY, F.: Sensing Behavior of $\mathrm{TiO}_{2}$ Thin Films Exposed to Air at Low Temperatures. Sensors and Actuators B, 67, 282-289, 2000. 